OPEN ACCESS

Edited by:

Nicola Mumoli,

ASST Ovest Milanese, Italy

Reviewed by:

Bernhard Maisch,

University of Marburg, Germany

Xuejuan Jin,

Fudan University, China

*Correspondence:

Kangting $\mathrm{Ji}$

jikt@wmu.edu.cn

Huifen Zhu

zhfen111@163.com

Specialty section:

This article was submitted to

General Cardiovascular Medicine,

a section of the journal

Frontiers in Cardiovascular Medicine

Received: 10 December 2020

Accepted: 14 June 2021

Published: 30 July 2021

Citation:

Xiang $H$, Xue Y, Chen Z, Yu Y, Peng Y, Wang J, Ji K and Zhu H (2021) The

Association Between Left Ventricular Hypertrophy and the Occurrence and Prognosis of Atrial Fibrillation: A

Meta-Analysis.

Front. Cardiovasc. Med. 8:639993.

doi: 10.3389/fcvm.2021.639993

\section{The Association Between Left Ventricular Hypertrophy and the Occurrence and Prognosis of Atrial Fibrillation: A Meta-Analysis}

\author{
Huaqiang Xiang ${ }^{1}$, Yangjing Xue ${ }^{1}$, Zhi Chen ${ }^{2}$, Yongwei Yu ${ }^{1}$, Yangpei Peng ${ }^{1}$, \\ Jinsheng Wang ${ }^{1}$, Kangting $\mathrm{Ji}^{{ }^{1 *}}$ and Huifen $\mathrm{Zhu}{ }^{1 *}$ \\ ${ }^{1}$ Department of Cardiology, The Second Affiliated Hospital and Yuying Children's Hospital, Wenzhou Medical University, \\ Wenzhou, China, ${ }^{2}$ Department of Medicine, Wenzhou Medical University, Wenzhou, China
}

Aims: The aim of this study was to perform a meta-analysis of studies of the association of left ventricular hypertrophy $(\mathrm{LVH})$ and atrial fibrillation (AF), especially the predictive and prognostic role of $\mathrm{LVH}$.

Methods and Results: We searched Medline, Embase, and the Cochrane Library from inception through 10 April 2020. A total of 16 cohorts (133,091 individuals) were included. Compared with the normal subjects, patients with LVH were more susceptible to AF (RR $=1.46,95 \% \mathrm{Cl}, 1.32-1.60)$. In patients with $\mathrm{AF}$ and $\mathrm{LVH}$, there was a higher risk of all-cause mortality during 3.95 years $(R R=1.60,95 \% \mathrm{Cl}, 1.42-1.79)$, and these patients were more likely to progress to persistent or paroxysmal $A F(R R=1.45,95 \% \mathrm{Cl}, 1.20$ 1.76) than were patients without $\mathrm{LVH}$. After catheter ablation of AF, patients with $\mathrm{LVH}$ were more likely to recur $(\mathrm{RR}=1.58,95 \% \mathrm{Cl}, 1.27-1.95)$.

Conclusion: $\mathrm{LVH}$ is strongly associated with $\mathrm{AF}$ and has a negative impact on outcome in patients with AF.

Keywords: left ventricular hypertrophy, atrial fibrillation, predictor, prognosis, electrocardiogram

\section{INTRODUCTION}

Atrial fibrillation (AF) is one of the major causes of stroke, heart failure, sudden death, and cardiovascular morbidity; it is the most common sustained arrhythmia worldwide. The number of patients with AF is predicted to rise steeply in the coming years (1). Hence, it is important to identify risk factors for AF as well as the outcomes associated with it. It has been demonstrated that left ventricular hypertrophy (LVH), detected by electrocardiogram or echocardiography, strongly predicted cardiovascular disease and its outcomes $(2,3)$. Likewise, Ramkumar et al. (4) stated that LVH detected by echocardiography would benefit the AF screening; Verdecchia et al. (5) indicated that LVH detected by electrocardiogram would improve risk stratification in anticoagulated patients with AF. To our knowledge, no study has systematically clarified the association between $\mathrm{LVH}$ and AF so far. Therefore, we performed a meta-analysis to comprehensively examine it. We sought to assess the predictive ability of left ventricular hypertrophy as risk factors for the development of AF, and we also attempted to determine whether the presence of LVH can identify that patients with AF have worse outcomes, including patients after the catheter ablation of AF. 


\section{METHODS AND RESULTS}

\section{Search Strategy and Selection Criteria}

We searched Medline, Embase, and Cochrane Library databases from inception through 10 April 2020 with the following terms: "atrial fibrillation," "atrial flutter," and "hypertrophy, left ventricular." We manually searched for additional eligible studies in the reference lists of retrieved publications and relevant meta-analyses in the discipline. Studies were included if the patients they enrolled met the following criteria: (1) clear diagnosis of left ventricular hypertrophy assessed by echocardiography or electrocardiography at baseline; (2) data on total new-onset AF events or diseases related to prognosis including stroke, death, and cardiovascular events; and (3) data on the effect value such as the hazard ratio (HR) or relative risk (RR) between patients with or without LVH. Studies were excluded if their subjects had one of the following conditions: history of cardiomyopathy or valvular or congenital heart disease; hepatic or renal disease; acute cardiovascular or cerebrovascular event; and hyperthyroidism. Studies of valvular atrial fibrillation were excluded. Cross-sectional studies were excluded. The detail of the selection process is shown in Figure 1.

\section{Definition}

Echocardiography-assessed LVH is preferably defined as LVMI $\geq 115 \mathrm{~g} \mathrm{~m}^{-2}$ in males and $\geq 95 \mathrm{~g} \mathrm{~m}^{-2}$ in females, but different cutoff points were also considered for eligibility. Electrocardiography-assessed LVH is based on a standard 7-lead or 12-lead ECG using a validated calculation [Sokolow-Lyon indices or Cornell voltage criteria (6)].

\section{Data Extraction and Quality Assessment}

Two reviewers (Xiang Huaqiang and Xue Yangjing) independently screened titles and abstracts based on inclusion. After eliminating irrelevant studies, full text reports were reviewed. Case studies and review articles were excluded. Subsequently, we performed hand search of all included cohort studies until no further relevant studies were identified. Disagreements between the two reviewers were resolved by the third reviewer (Zhu Huifen). Then the two investigators (Xiang Huaqiang and Xue Yangjing) independently reviewed the main reports and supplementary materials and extracted information into an electronic database: study and patients characteristics, study design, interventions, the number of events of incident AF or diseases related to prognosis in each group, and the duration of follow-up. Any discrepancies regarding the extraction of data were resolved by an additional investigator (Zhu Huifen). The Newcastle-Ottawa Scale was used for the quality assessment of cohort studies. This scale appoints a maximum of nine stars to each study: four stars for the adequate selection of the two groups, two stars for comparability of groups on the basis of the design and analysis, and three stars for the adequate ascertainment of the exposure in both groups (7). Detailed data are presented in Table $\mathbf{1 .}$

\section{Data Analysis}

Most of the studies we included presented adjusted HR in the published articles, and we self-calculated the RR from $2 \times 2$ tables

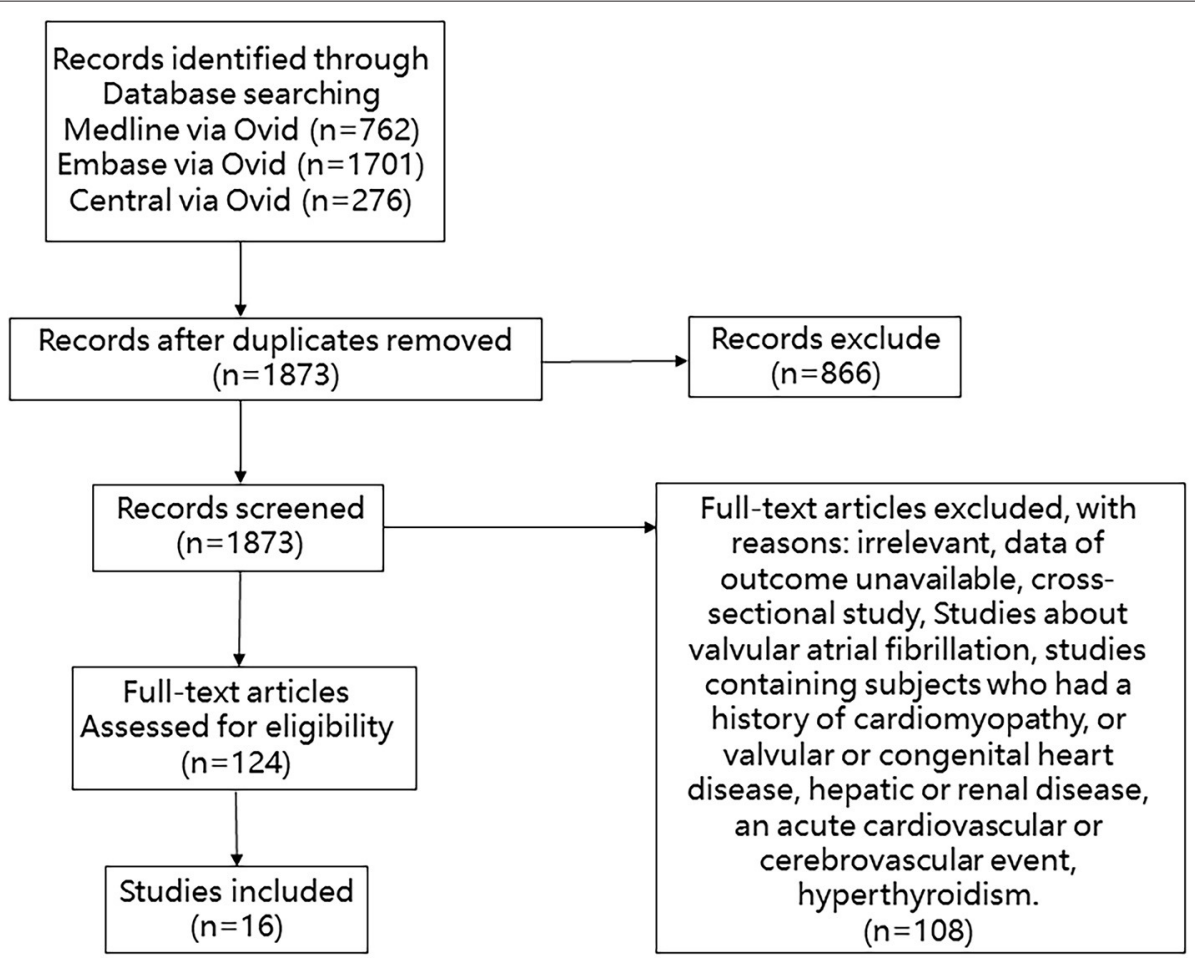

FIGURE 1 | Flowchart of studies considered for inclusion. 
TABLE 1 | Quality assuagement of cohort studies.

\begin{tabular}{lccc}
\hline References & Selection & Comparability & Exposure \\
\hline Jeong (8) & $\star$ & - & $\star \star \star$ \\
Hamada and Muto (9) & $\star \star$ & $\star \star$ & $\star \star \star$ \\
Renate et al. (10) & $\star \star$ & $\star$ & $\star \star$ \\
MacFarlane et al. (11) & $\star \star$ & $\star \star$ & $\star \star$ \\
Chamberlain et al. (12) & $\star \star \star$ & $\star$ & $\star \star \star$ \\
Patel et al. (13) & $\star \star \star$ & $\star \star$ & $\star \star$ \\
Jonathan et al. (14) & $\star \star \star$ & $\star \star$ & $\star \star \star$ \\
Lehtonen et al. (15) & $\star \star \star$ & - & $\star \star$ \\
Okin (16) & $\star \star \star$ & $\star$ & $\star \star$ \\
Verdecchia et al. (17) & $\star \star \star$ & $\star \star$ & $\star \star$ \\
Padfield et al. (18) & $\star \star \star$ & $\star \star$ & $\star \star$ \\
Hijazi et al. (19) & $\star \star \star$ & $\star \star$ & $\star \star$ \\
Verdecchia et al. (5) & $\star \star \star \star$ & $\star \star$ & $\star \star \star$ \\
Badheka et al. (20) & $\star \star \star$ & $\star$ & $\star \star$ \\
De With et al. (21) & $\star \star$ & $\star$ & $\star \star$ \\
Im et al. (22) & $\star \star \star \star$ & $\star \star$ \\
Akkaya et al. (23) & $\star \star$ \\
Li et al. (24) & $\star \star$ \\
\hline & $\star \star$ & $\star$ \\
\hline
\end{tabular}

for the remaining studies that did not. Effect estimates along with their $95 \%$ confidence intervals (CIs) by LVH were pooled results using fixed-effects models. The $\mathrm{I}^{2}$ statistic was calculated as a measure of the proportion of the overall variation that is attributable to the between-study heterogeneity. Analyses were conducted using STATA 14.

\section{RESULTS}

We included 16 studies in the end. At first, we included 18 cohort studies and 10 studies related to the predictive role of $\mathrm{LVH}$ in new-onset AF. In order to investigate whether left ventricular hypertrophy detected by electrocardiogram (ECG-LVH) would increase the risk of AF independently, we excluded one study that defined LVH via echocardiography. In addition, in six studies that investigated the role of $\mathrm{LVH}$ in the prognosis of AF, three studies were post-hoc analysis and two studies used the same original trials, thus, one of them was excluded. In short, nine studies investigated the predictive role of $\mathrm{LVH}$, five studies investigated the prognostic role of $\mathrm{LVH}$, and two studies investigated the difference of recurrence risk after catheter ablation of subjects with or without LVH.

\section{The Association Between LVH and New-Onset AF}

The baseline characteristics of patients who took part in the research investigating the predictive role of $\mathrm{LVH}$ are shown in Table 2A. LVH was all defined by electrocardiogram. Particularly, we can divide the nine studies into two subgroups according to baseline blood pressure. Six out of the nine studies were based on the population including both hypertension and normotension, while the remaining three studies were based on hypertension patients only. In all, the pooled population consisted of 118,195 subjects, in which there were 3,815 participants with LVH and 105,549 participants without (one study did not provide the specific number of participants). The duration of follow-up ranged from 3.2 to 11.9 years, with a mean of 7.7 years. The mean age was $55.4 \pm 11$ years, and $58 \%$ of the patients were men. During the follow-up, a total of 3,235 AF events were reported among 115,860 patients, while 258 subjects had LVH. Seven out of the nine manuscripts reported adjusted HR of incidence AF in patients with $\mathrm{LVH}$, and we self-calculated the RR from $2 \times 2$ tables for the remaining two studies. As illustrated in Figure 2, $\mathrm{LVH}$ is related to higher risk of new-onset $\mathrm{AF}$ in the population based on mixed blood pressure $\left(\mathrm{RR}=1.65,95 \% \mathrm{CI}, 1.44-1.89, I^{2}\right.$ $=55.2 \%)$ and the population based on hypertension $(\mathrm{RR}=1.28$, $95 \%$ CI, $\left.1.11-1.47, I^{2}=19.9 \%\right)$.

\section{The Association Between LVH and the Prognostic of AF}

Table 2B displays the baseline characteristics of patients who participated in the five studies that investigated the prognostic role of LVH in AF patients. Due to the limited research assessing the prognostic role of LVH in AF, we included studies that defined LVH via electrocardiogram and echocardiography. Among them, one study defined LVH by electrocardiogram, three studies defined LVH by echocardiography, and one study defined LVH by electrocardiogram or echocardiography. The pooled population consisted of 14,119 subjects, in which there were 3,922 participants with $\mathrm{LVH}$ and 10,197 participants without. The duration of follow-up ranged from 2 to 7.2 years, with a mean of 5.0 years. The mean age was $69.4 \pm 10.4$ years, and $62.8 \%$ of the patients were men. In the included five manuscripts, three studies reported the HR of all-cause mortality, and three studies reported the HR of AF progression. Participants with LVH had a higher risk of AF progression ( $\mathrm{RR}=1.45,95 \%$ CI $1.20-1.76, I^{2}=0 \%$, Figure 3$)$ and all-cause mortality $(\mathrm{RR}=1.60,95 \% \mathrm{CI} 1.42-1.79$, $I^{2}=77.0 \%$, Figure 4).

Table $2 \mathrm{C}$ reports the characteristics of patients in the two studies that investigated the different recurrence risk of $\mathrm{AF}$ after catheter ablation with or without LVH. One study defined $\mathrm{LVH}$ by electrocardiogram, and the other study defined $\mathrm{LVH}$ by echocardiography. The pooled population consisted of 777 subjects, in which there were 318 participants with LVH and 459 participants without. The mean follow-up was 26.5 months. The mean age was $62.8 \pm 11.3$ years, and $70.1 \%$ of the patients were men. During the mean follow-up of 26.5 months, 131 patients developed AF recurrence in 459 participants without LVH, while 147 patients developed AF recurrence in 318 participants with $\mathrm{LVH}$. In other words, AF patients with $\mathrm{LVH}$ have a higher risk of developing AF recurrence after the surgery than those without LVH $\left(\mathrm{RR}=1.58,95 \%\right.$ CI $1.27-1.95, I^{2}=0 \%$, Figure 5).

\section{DISCUSSION}

One of our findings was that LVH assessed by ECG was a significant predictor of AF. AF has a high prevalence worldwide and was related to many complications and higher all-cause mortality rates (1). ECG is a relatively inexpensive, 
TABLE 2A | Baseline clinical characteristics in patients who were in the studies that investigated the association between LVH and new-onset AF.

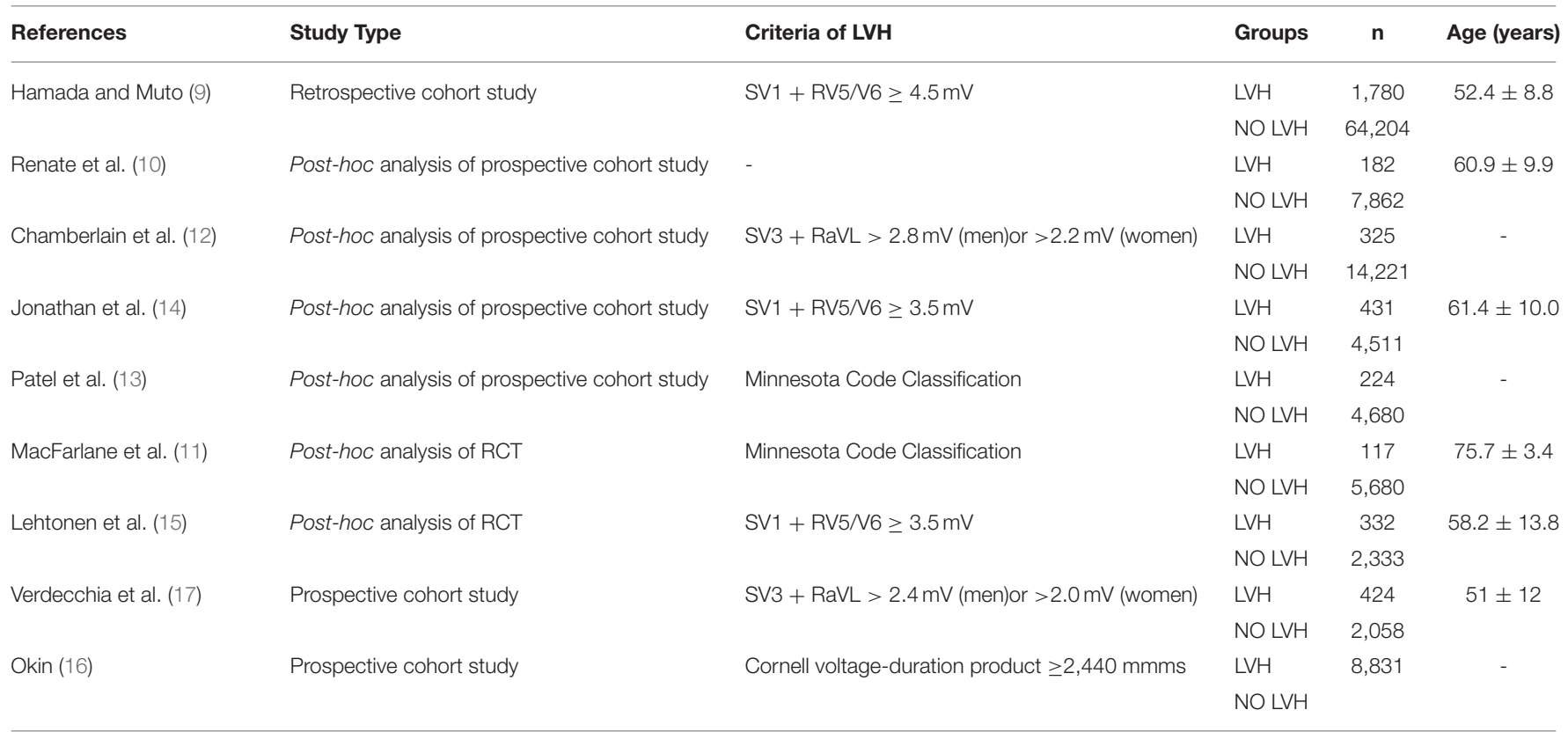

$L V H$, left ventricular hypertrophy; $R C T$, randomized controlled trial.

Cornell voltage-duration product, the product of QRS duration times the Cornell voltage combination (RaVL + SV3, with 6 mm added in women).

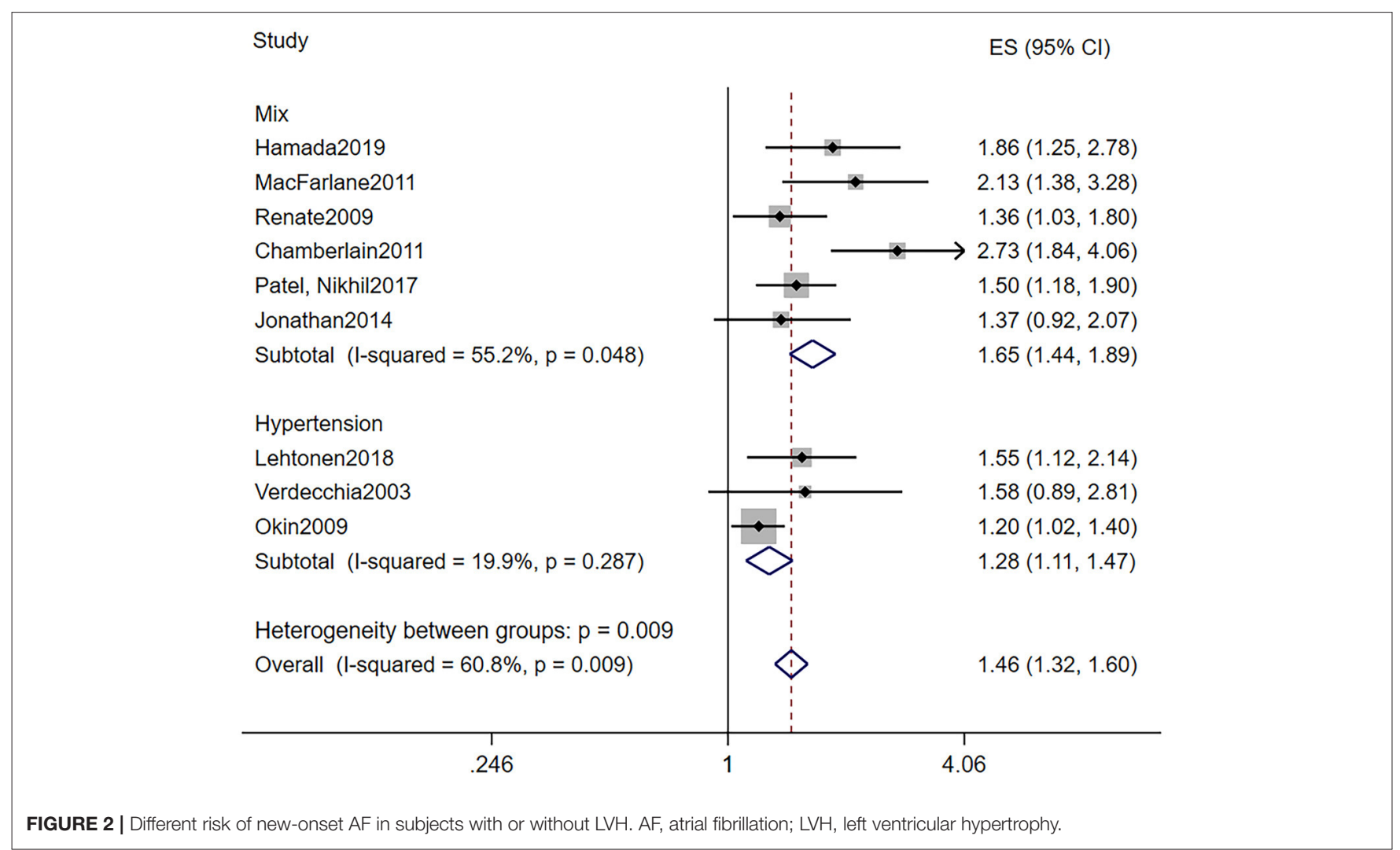

convenient, and widely available tool for screening disease. Hence, we sought to find out whether ECG could predict the development of AF independently. As illustrated in Figure 2, subjects with ECG-LVH in both subgroups stratified by the baseline blood pressure were at a higher risk for the incidence of AF. Hypertension not only is a risk factor of cardiovascular complications but also increases the risk for the development of atrial fibrillation. Okin et al. (25) determined that the regression 
TABLE 2B | Baseline clinical characteristics in patients who were in the studies that investigated the association between LVH and the prognosis of AF.

\begin{tabular}{|c|c|c|c|c|c|c|c|c|c|c|}
\hline References & Study type & Criteria of LVH & Groups & $\mathbf{n}$ & Age (years) & Male (\%) & $\begin{array}{c}\text { Paroxysmal } \\
\text { AF }\end{array}$ & OAC (\%) & $\begin{array}{c}\text { CHA2DS2- } \\
\text { VASc } \\
\text { Score }\end{array}$ & $\begin{array}{c}\text { Follow-Up } \\
\text { (years) }\end{array}$ \\
\hline Im et al. (22) & $\begin{array}{l}\text { Retrospective cohort } \\
\text { study }\end{array}$ & - & LVH & 93 & $62.8 \pm 11.1$ & $256(60.8)$ & $100 \%$ & 95(22.6) & $1.92 \pm 1.4$ & $6.1 \pm 4.9$ \\
\hline [-9pt] & & & $\begin{array}{l}\mathrm{NO} \\
\mathrm{LVH}\end{array}$ & 328 & & & & & & \\
\hline Verdecchia et al. (5) & $\begin{array}{l}\text { Post-hoc analysis of } \\
\text { RCT }\end{array}$ & $\begin{array}{l}\text { SV3 + RaVL > } \\
2.4 \mathrm{mV} \text { (men) } \\
\text { or > } 2.0 \mathrm{mV} \\
\text { (women) }\end{array}$ & $\mathrm{LVH}$ & 2353 & $71.3 \pm 9$ & $1,413(60)$ & $15 \%$ & $1,568(67)$ & $3.70 \pm 1.4$ & 2.0 \\
\hline [-23pt] & & & $\begin{array}{l}\mathrm{NO} \\
\mathrm{LVH}\end{array}$ & 8019 & $71.1 \pm 9$ & $5,358(67)$ & $16 \%$ & $5,701(71)$ & $3.36 \pm 1.3$ & \\
\hline Badheka et al. (20) & $\begin{array}{l}\text { Post-hoc analysis of } \\
\text { RCT }\end{array}$ & $\begin{array}{l}\left(\text { LVMI) }>95 \mathrm{~g} / \mathrm{m}^{2}\right. \\
\text { in (women) } \\
\text { or }>115 \mathrm{~g} / \mathrm{m}^{2} \\
\text { (men). }\end{array}$ & LVH & 1373 & $69.0 \pm 8.1$ & $760(55.4)$ & $49.80 \%$ & - & - & $3.5 \pm 1.3$ \\
\hline$[-25 p t]$ & & & $\begin{array}{l}\mathrm{NO} \\
\mathrm{LVH}\end{array}$ & 732 & $70.1 \pm 8.1$ & $443(60.6)$ & $57.90 \%$ & & & \\
\hline Padfield et al. (18) & $\begin{array}{l}\text { Prospective cohort } \\
\text { study }\end{array}$ & - & $\mathrm{LVH}$ & 53 & $61.2 \pm 14.2$ & $289(38.5)$ & $100 \%$ & $216(28.6)$ & $0.22 \pm 0.41$ & 6.35 \\
\hline [-10pt] & & & $\begin{array}{l}\mathrm{NO} \\
\mathrm{LVH}\end{array}$ & 700 & & & & & & \\
\hline De With et al. (21) & $\begin{array}{l}\text { Prospective cohort } \\
\text { study }\end{array}$ & $\begin{array}{l}\text { (LVMI) > } 95 \mathrm{~g} / \mathrm{m}^{2} \\
\text { in (women) } \\
\text { or }>115 \mathrm{~g} / \mathrm{m}^{2} \\
\text { (men). }\end{array}$ & LVH & 50 & $49 \pm 9$ & $354(76)$ & $70 \%$ & - & $1 \pm 0.5$ & 7.2 \\
\hline [-26pt] & & & $\begin{array}{l}\mathrm{NO} \\
\mathrm{LVH}\end{array}$ & 418 & & & & & & \\
\hline
\end{tabular}

LVH, left ventricular hypertrophy; RCT, randomized controlled trial; LVMI, left ventricular mass index.

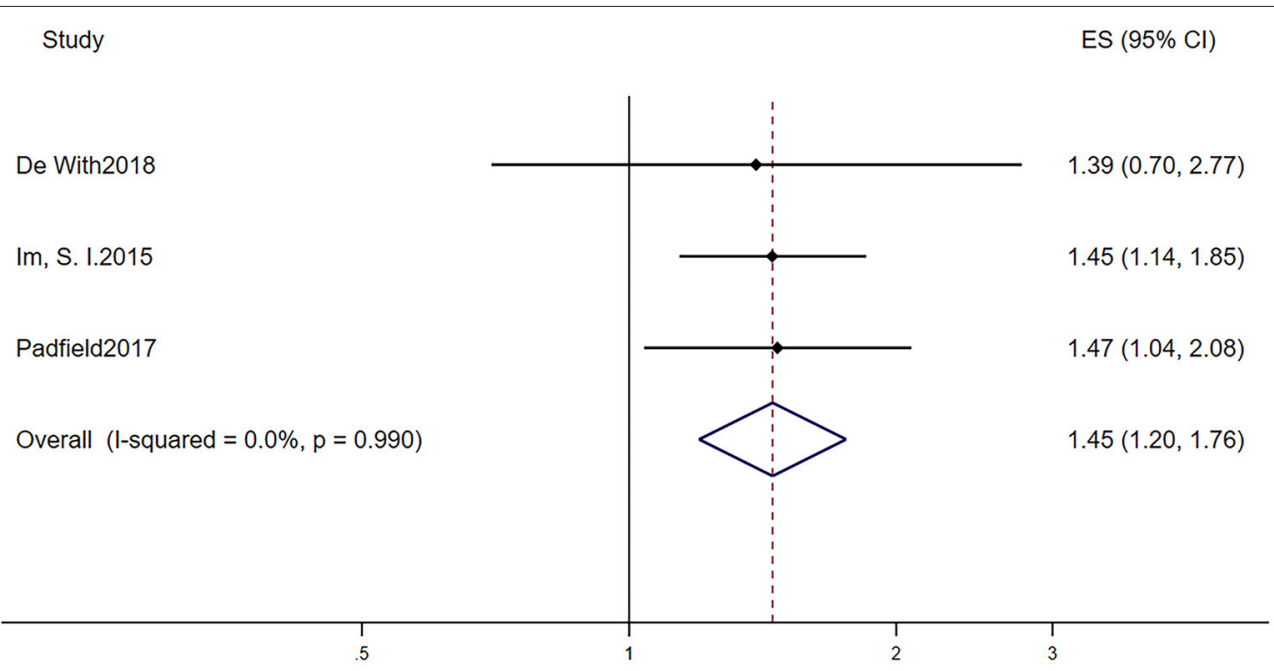

FIGURE 3 | Different risk of AF progression in AF subjects with or without LVH. AF, atrial fibrillation; LVH, left ventricular hypertrophy.

of ECG-LVH would decrease the incidence of new-onset AF in patients with hypertension. These findings suggest that therapy aimed to decrease the LVH may be required. However, this result was heterogeneous. Other factors may account for the finding. First, although cases of LVH were all assessed by ECG, there were varying criteria. Jonathan et al. (14) analyzed 11 of
ECG-LVH criteria in terms of their associations with incident AF and found that only 3 of the 11 ECG-LVH criteria had significant associations with $\mathrm{AF}$ after adjustment. Second, in the multivariate analysis, the models were different; some studies were adjusted only for sex and age, while some were adjusted for all risk factors, and difference in baseline characteristics and sample sizes would 


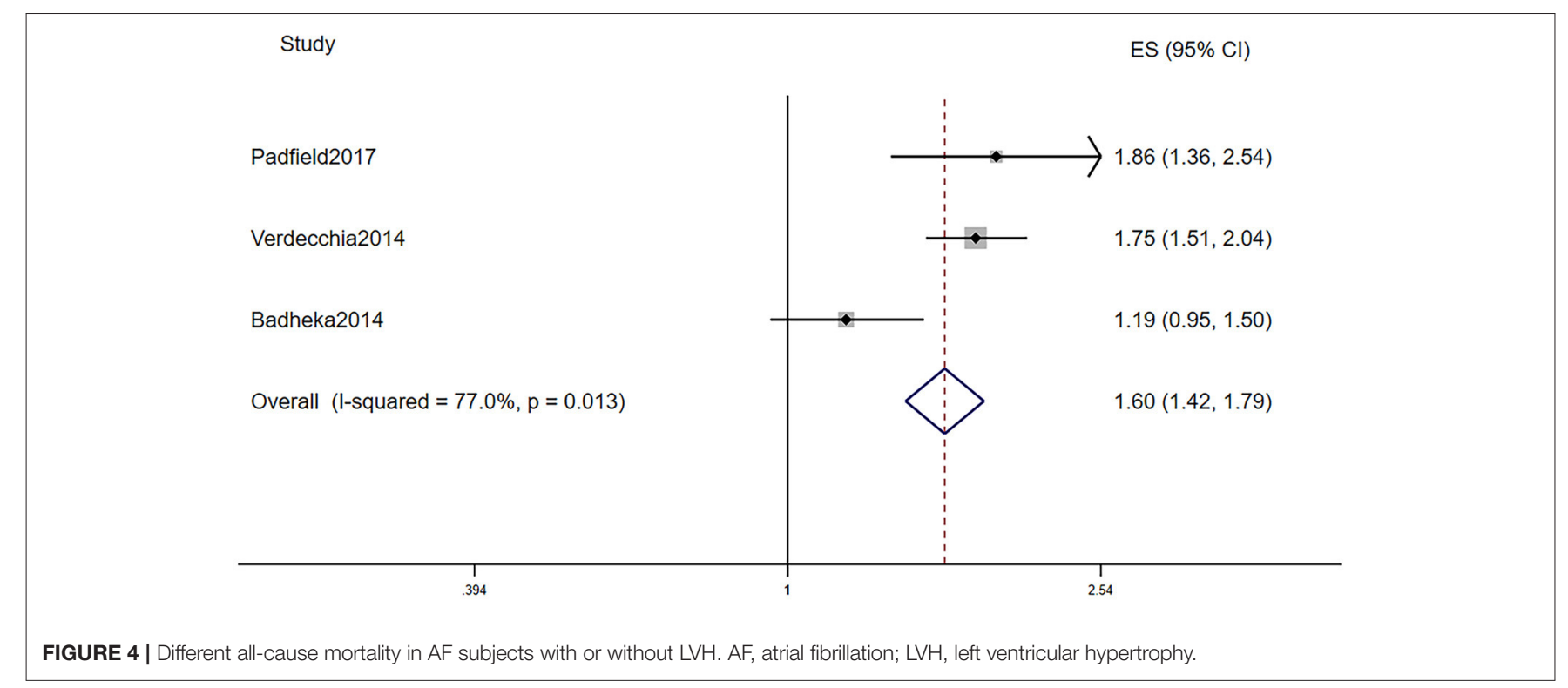

TABLE 2C | Baseline clinical characteristics in patients who were in the studies that investigated the association between LVH and the recurrence of AF after catheter ablation.

\begin{tabular}{|c|c|c|c|c|c|c|c|c|}
\hline References & Study type & Criteria of LVH & Groups & $\mathbf{n}$ & Age (years) & Male (\%) & Paroxysmal AF (\%) & Follow-Up \\
\hline \multirow[t]{2}{*}{ Akkaya et al. (23) } & $\begin{array}{l}\text { Retrospective } \\
\text { cohort study }\end{array}$ & $\begin{array}{l}\mathrm{LVMI}>104 \mathrm{~g} / \mathrm{m}^{2} \\
\text { (women) } \\
\text { Or }>116 \mathrm{~g} / \mathrm{m}^{2} \\
\text { (men) }\end{array}$ & LVH & 111 & $65.4 \pm 11.3$ & 95 (77.9) & $49.90 \%$ & $11.1 \pm 3.8$ months \\
\hline & & & NO LVH & 246 & $64.8 \pm 12.3$ & $165(58.5)$ & & \\
\hline \multirow[t]{2}{*}{ Li et al. (24) } & $\begin{array}{l}\text { Prospective } \\
\text { cohort study }\end{array}$ & $\begin{array}{l}\text { Romhilt-Estes } \\
\text { point score } \\
\geq 5 \text { points }\end{array}$ & $\mathrm{LVH}$ & 207 & $61.6 \pm 10.8$ & $144(66.1)$ & $100 \%$ & 42 months \\
\hline & & & $\mathrm{NO}$ LVH & 213 & $60.2 \pm 9.8$ & $141(64.7)$ & & \\
\hline
\end{tabular}

LVH, left ventricular hypertrophy; LVMI, left ventricular mass index.

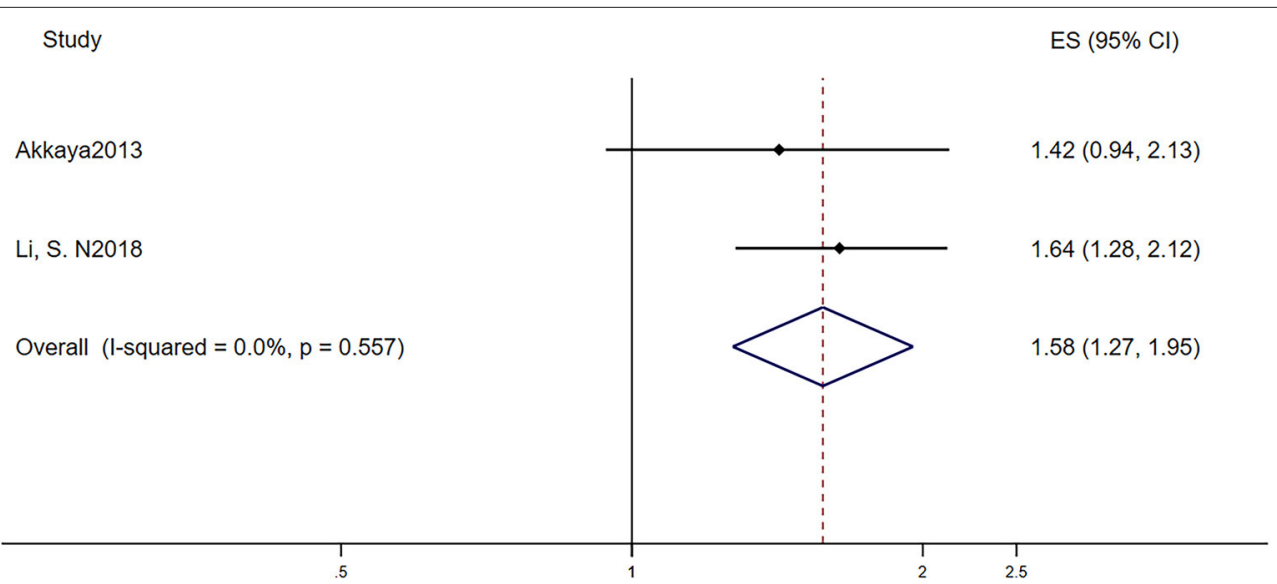

FIGURE 5 | Different risk of recurrence after catheter ablation in AF subjects with or without LVH. AF, atrial fibrillation; LVH, left ventricular hypertrophy.

both contribute to the heterogeneity. Finally, some studies were post-hoc analyses based on other trials, and this is a potential source of uncontrolled bias and confounding factors.
Another remarkable finding was that AF in the context of $\mathrm{LVH}$ was associated with worse outcomes. These patients were more susceptible to AF progression (i.e., from paroxysmal AF 
to persistent or permanent $\mathrm{AF}$ ) and death. AF is considered as a progressive disease; the overall progression rate is $>5 \%$ per annum (26). Benjamin et al. (27) indicated that persistent AF would result in a higher risk of thromboembolic events and worse survival compared with those with paroxysmal AF. To identify patients who were likely to progress to sustained AF at 1-year follow-up, de Vos et al. (28) developed the HATCH score (the acronym stands for hypertension, age [75 years and older), transient ischemic attack or stroke (2 points), chronic obstructive pulmonary disease, and heart failure ( 2 points)]. They found that nearly half of subjects with a HATCH score higher than 5 and only $6 \%$ of patients with a HATCH score of 0 progressed to sustained AF within 1 year. To evaluate the accuracy of the HATCH score, Barrett et al. (29) conducted a retrospective cohort including 253 AF patients and found that 61 participants progressed to sustained AF within 1 year. Nevertheless, only two participants had scores $>5$, suggesting that the $\mathrm{HATCH}$ score did not identify patients who were actually at high risk for AF progression. Refinement of this decision aid is needed. It is feasible to add $\mathrm{LVH}$ as a predictor of AF prognosis, and that would be definitely helpful for physicians to make clinical decision that may improve the progression of AF.

$\mathrm{AF}$ is independently associated with a 2 -fold increased risk of all-cause mortality in women and a 1.5 -fold increase in men (30). We demonstrated that patients with AF in the context of LVH had a 1.46-fold increased risk than those without LVH. Furthermore, Badheka et al. (20) divided participants with LVH into three groups (mildly abnormal, moderately abnormal, or severely abnormal) according to the American Society of Echocardiography criteria. They found that higher LV mass correlated with greater degrees of association between LVH and all-cause mortality. In addition, Verdecchia et al. (5) found that excess all-cause mortality associated with $\mathrm{LVH}$ was greater in patients with lower (from 0 to 2) than higher (>3) $\mathrm{CHA}_{2} \mathrm{DS}_{2}$ VASc scores, suggesting that ECG-LVH may be more suitable as a prognostic marker in patients with lower $\mathrm{CHA}_{2} \mathrm{DS}_{2}$-VASc scores. To sum up, LVH is a prognostic predictor of all-cause mortality in those with severe $\mathrm{LVH}$ and low $\mathrm{CHA}_{2} \mathrm{DS}_{2}$-VASc scores. Consequently, it is necessary and favorable to screen out the high-risk groups, and a corresponding therapy is needed. There are two strategies for treatment of atrial fibrillation: one is rhythm control with antiarrhythmic drugs to maintain sinus rhythm, and the other is rate control, allowing atrial fibrillation to persist. In patients with AF in the context of LVH, Badheka et al. (20) reported that $\mathrm{LVH}$ was a significant independent predictor of mortality, especially in patients managed with rhythm control, suggesting that strict rate control may be associated with better outcomes than is rhythm control. Nevertheless, there is significant heterogeneity in our result. When we pooled

\section{REFERENCES}

1. Kirchhof P, Benussi S, Kotecha D, Ahlsson A, Atar D, Casadei B, et al. 2016 ESC Guidelines for the management of atrial fibrillation developed in collaboration with EACTS. Eur $J$ Cardio-Thoracic Surg. (2016) 50:E1-E88. doi: 10.1016/j.rec.2016. 11.033 the results using random-effects models or excluded any of the studies, the heterogeneity remained. The incorporation of studies using either echocardiographic or electrocardiographic assessment of LVH may account for this finding. Moreover, although the result was identified using multivariable analysis, the adjusted Cox model was not totally the same in the four trials; differences of patterns of $\mathrm{AF}$, length of follow-up, $\mathrm{CHA}_{2} \mathrm{DS}_{2}$ VASc scores, and other baseline characteristics all generate heterogeneity. Finally, the design structure of the trials and posthoc analysis may contribute to the heterogeneity.

Catheter ablation of AF, generally a second-line treatment, is more effective than antiarrhythmic drug therapy in rhythm control (31). However, the recurrence of AF within 1 year was not uncommon. Previous studies (32) demonstrated that left atrial fibrosis predicted recurrence. AF patients with LVH also had a higher degree of left atrial fibrosis (33). Compared with screening for left atrial fibrosis, screening for $\mathrm{LVH}$ is much more convenient and has low cost. More large randomized controlled trials are needed to demonstrate the independence of $\mathrm{LVH}$ as a predictor in the recurrence of AF.

\section{LIMITATION}

The present study has some limitations, including differences among the study designs, sample characteristics, and quality of the included studies. The difference criteria of LVH may restrict the credibility of the results; more large randomized controlled studies are highly needed.

\section{DATA AVAILABILITY STATEMENT}

The original contributions presented in the study are included in the article/supplementary material, further inquiries can be directed to the corresponding authors.

\section{AUTHOR CONTRIBUTIONS}

$\mathrm{KJ}$ and $\mathrm{HZ}$ make the conception and design of the review. HX make the analysis and interpretation of the data as well as drafting the manuscript. YY, YX, ZC, YP, and JW make the critical revision of the manuscript for important intellectual content. All authors contributed to the article and approved the submitted version.

\section{FUNDING}

This work was supported by the Scientific Research Foundation of the Science and Technology Department of Wenzhou City (No. Y20170483).

2. Abdou E, Arend FLS, Ron TvD, Jeroen JB, Harm HHF, Peter GN, et al. Prognostic implications of stress Tc-99m tetrofosmin myocardial perfusion imaging in patients with left ventricular hypertrophy. J Nucl Cardiol. (2007) 14:550-4. doi: 10.1016/j.nuclcard.2007.04.023

3. Manyari DE. Prognostic implications of echocardiographically determined left ventricular mass in the Framingham Heart Study. N Engl J Med. (1990) 323:1706-7. doi: 10.1056/NEJM199012133232413 
4. Ramkumar S, Ochi A, Kawakami H, Yang H, Potter EL, D'Elia N, et al. Echocardiographic risk assessment to guide screening for atrial fibrillation. J Am Soc Echocardiogr. (2019) 32:1259-67. doi: 10.1016/j.echo.2019.07.003

5. Verdecchia P, Reboldi G, Di Pasquale G, Mazzotta G, Ambrosio G, Yang S, et al. Prognostic usefulness of left ventricular hypertrophy by electrocardiography in patients with atrial fibrillation (from the randomized evaluation of long-term anticoagulant therapy study). Am J Cardiol. (2014) 113:669-75. doi: 10.1016/j.amjcard.2013.10.045

6. Philippe G, Emilie J, Paul C, Antoine C, Georgios P, Sunthareth Y. ECG detection of left ventricular hypertrophy: the simpler, the better? J Hypertens. (2012) 30:990-6. doi: 10.1097/HJH.0b013e3283524961

7. Gláucia FC, Marcos RdS, Tatiani Oliveira F, Ana R. Efficacy of antileishmania therapy in visceral leishmaniasis among HIV infected patients: a systematic review with indirect comparison. PLoS Negl Trop Dis. (2013) 7:e2195. doi: 10.1371/journal.pntd.0002195

8. Jeong JH. Prevalence of and risk factors for atrial fibrillation in Korean adults older than 40 years. J Korean Med Sci. (2005) 20:26-30. doi: $10.3346 / \mathrm{jkms} .2005 .20 .1 .26$

9. Hamada R, Muto S. Simple risk model and score for predicting of incident atrial fibrillation in Japanese. J Cardiol. (2019) 73:6572. doi: $10.1016 / j . j j c c .2018 .06 .005$

10. Renate BS, Lisa MS, Daniel L, Michael JP, Joseph MM, Ralph BDA, et al. Development of a risk score for atrial fibrillation (Framingham Heart Study): a community-based cohort study. Lancet. (2009) 373:73945. doi: 10.1016/S0140-6736(09)60443-8

11. MacFarlane PW, Murray H, Sattar N, Stott DJ, Ford I, Buckley B, et al. The incidence and risk factors for new onset atrial fibrillation in the PROSPER study. Europace. (2011) 13:634-9. doi: 10.1093/europace/eur016

12. Chamberlain AM, Agarwal SK, Folsom AR, Soliman EZ, Chambless LE, Crow $\mathrm{R}$, et al. A clinical risk score for atrial fibrillation in a biracial prospective cohort (from the atherosclerosis risk in communities [ARIC] Study). Am J Cardiol. (2011) 107:85-91. doi: 10.1016/j.amjcard.2010.08.049

13. Patel N, O'Neal WT, Whalen SP, Soliman EZ. Electrocardiographic left ventricular hypertrophy predicts atrial fibrillation independent of left ventricular mass. Ann Noninvasive Electrocardiol. (2017) 22:1-5. doi: $10.1111 /$ anec. 12419

14. Jonathan C, Aditya J, Elsayed ZS, Eliseo G, Alvaro A, Susan RH, et al. Association of electrocardiographic and imaging surrogates of left ventricular hypertrophy with incident atrial fibrillation: MESA (multiethnic study of atherosclerosis). J Am Coll Cardiol. (2014) 63:200713. doi: 10.1016/j.jacc.2014.01.066

15. Lehtonen AO, Langen VL, Porthan K, Kahonen M, Nieminen MS, Jula AM, et al. Electrocardiographic predictors of atrial fibrillation in nonhypertensive and hypertensive individuals. J Hypertens. (2018) 36:187481. doi: 10.1097/HJH.0000000000001760

16. Okin PM. Serial evaluation of electrocardiographic left ventricular hypertrophy for prediction of risk in hypertensive patients. J Electrocardiol. (2009) 42:584-8. doi: 10.1016/j.jelectrocard.2009.06.020

17. Verdecchia P, Reboldi G, Gattobigio R, Bentivoglio M, Borgioni C, Angeli $\mathrm{F}$, et al. Atrial fibrillation in hypertension: predictors and outcome. Hypertension. (2003) 41:218-23. doi: 10.1161/01.HYP.0000052830.02773.E4

18. Padfield GJ, Steinberg C, Swampillai J, Qian H, Connolly SJ, Dorian P, et al. Progression of paroxysmal to persistent atrial fibrillation: 10-year follow-up in the Canadian registry of atrial fibrillation. Heart Rhythm. (2017) 14:8017. doi: 10.1016/j.hrthm.2017.01.038

19. Hijazi Z, Verdecchia P, Oldgren J, Andersson U, Reboldi G, Di Pasquale $\mathrm{G}$, et al. Cardiac biomarkers and left ventricular hypertrophy in relation to outcomes in patients with atrial fibrillation: experiences from the RE - LY trial. J Am Heart Assoc. (2019) 8:e010107. doi: 10.1161/JAHA.118.010107

20. Badheka AO, Shah N, Grover PM, Patel NJ, Chothani A, Mehta K, et al. Outcomes in atrial fibrillation patients with and without left ventricular hypertrophy when treated with a lenient rate-control or rhythm-control strategy. Am J Cardiol. (2014) 113:1159-65. doi: 10.1016/j.amjcard.2013.12.021

21. De With RR, Marcos EG, Van Gelder IC, Rienstra M. Atrial fibrillation progression and outcome in patients with young-onset atrial fibrillation. Europace. (2018) 20:1750-7. doi: 10.1093/europace/euy028
22. Im SI, Chun KJ, Park SJ, Park KM, Kim JS, On YK. Long-term prognosis of paroxysmal atrial fibrillation and predictors for progression to persistnt or chronic atrial fibrillation in the Korean population. J Kor Med Sci. (2015) 30:895-902. doi: 10.3346/jkms.2015.30.7.895

23. Akkaya M, Higuchi K, Koopmann M, Burgon N, Erdogan E, Damal $\mathrm{K}$, et al. Relationship between left atrial tissue structural remodelling detected using late gadolinium enhancement MRI and left ventricular hypertrophy in patients with atrial fibrillation. Europace. (2013) 15:172532. doi: 10.1093/europace/eut147

24. Li SN, Wang L, Dong JZ, Yu RH, Long DY, Tang RB, et al. Electrocardiographic left ventricular hypertrophy predicts recurrence of atrial arrhythmias after catheter ablation of paroxysmal atrial fibrillation. Clin Cardiol. (2018) 41:797-802. doi: 10.1002/clc.22957

25. Okin PM, Wachtell K, Devereux RB, Harris KE, Jern S, Kjeldsen SE, et al. Regression of electrocardiographic left ventricular hypertrophy and decreased incidence of new-onset atrial fibrillation in patients with hypertension. JAMA. (2006) 296:1242-8. doi: 10.1001/jama.296.10.1242

26. Stanley N, Eduard G, Irina S, Francisco GC, Irene V, Jonathan LH, et al. Early management of atrial fibrillation to prevent cardiovascular complications. European Heart J. (2014) 35:1448-56. doi: 10.1093/eurheartj/ehu028

27. Benjamin AS, Anne SH, Yuliya L, Manesh RP, Günter B, Graeme JH, et al. Higher risk of death and stroke in patients with persistent vs. paroxysmal atrial fibrillation: results from the ROCKET-AF trial. Eur Heart J. (2015) 36:288-96. doi: 10.1093/eurheartj/ehu359

28. de Vos CB, Pisters R, Nieuwlaat R, Prins MH, Tieleman RG, Coelen R-JS, et al. Progression from paroxysmal to persistent atrial fibrillation. J Am Coll Cardiol. (2010) 55:725. doi: 10.1016/j.jacc.2009.11.040

29. Barrett TW, Self WH, Wasserman BS, McNaughton CD, Darbar D. Evaluating the HATCH score for predicting progression to sustained atrial fibrillation in ED patients with new atrial fibrillation. Am J Emerg Med. (2013) 31:79297. doi: 10.1016/j.ajem.2013.01.020

30. Benjamin EJ, Wolf PA, Agostino RBD, Silbershatz H, Kannel WB, Levy D. Impact of atrial fibrillation on the risk of death: the Framingham Heart Study. Circulation. (1998) 98:946-52. doi: 10.1161/01.CIR.98.10.946

31. Gareth JW, Moloy D, Laura JB, Sandeep P, Tom W, Dhiraj G. Efficacy of catheter ablation for persistent atrial fibrillation: a systematic review and meta-analysis of evidence from randomized and nonrandomized controlled trials. Circulation. (2014) 7:841-52. doi: 10.1161/CIRCEP.114.0 01759

32. Nazem, Marcos D, Chris M, Nathan S, Gaston V, Suman K, et al. Atrial fibrosis helps select the appropriate patient and strategy in catheter ablation of atrial fibrillation: a DE-MRI guided approach. J Cardiovas Electrophysiol. (2011) 22:16-22. doi: 10.1111/j.1540-8167.2010.01876.x

33. Caroline M, Jonathan MK, Steven JS, Andrew WT, Geoffrey L, Ilona B, et al. Atrial electrical and structural changes associated with longstanding hypertension in humans: implications for the substrate for atrial fibrillation. J Cardiovasc Electrophysiol. (2011) 22:1317-24. doi: 10.1111/j.1540-8167.2011.02125.x

Conflict of Interest: The authors declare that the research was conducted in the absence of any commercial or financial relationships that could be construed as a potential conflict of interest.

Publisher's Note: All claims expressed in this article are solely those of the authors and do not necessarily represent those of their affiliated organizations, or those of the publisher, the editors and the reviewers. Any product that may be evaluated in this article, or claim that may be made by its manufacturer, is not guaranteed or endorsed by the publisher.

Copyright $\odot 2021$ Xiang, Xue, Chen, Yu, Peng, Wang, Ji and Zhu. This is an open-access article distributed under the terms of the Creative Commons Attribution License (CC BY). The use, distribution or reproduction in other forums is permitted, provided the original author(s) and the copyright owner(s) are credited and that the original publication in this journal is cited, in accordance with accepted academic practice. No use, distribution or reproduction is permitted which does not comply with these terms. 